\title{
Reflexões para educar organizações através de pessoas
}

\section{Reflections to educate organizations people}

\section{Reflexiones para educar a las organizaciones através de personas}

Este artigo promove reflexões com objetivo de auxiliar na reeducação organizacional e em seus processos mediante pessoas, ou seja, os profissionais da organização.

Para tanto, contextualiza para as organizações modernas, extraindo do arcabouço da Qualidade, quatro conceitos ou técnicas: Kaizen, Reengenharia, Benchmarking e PDCA. $E$ a partir desses conceitos, produz reflexões crescentes, enfatizando o papel humano nas organizações.

Conclui o artigo mostrando a importância das pessoas em uma organização.
This article promotes reflections in order to assist in organizational and reeducation processes through people, namely, professionals in the organization.

To do so, modern organizations contextualizes extracting the quality framework, four concepts or techniques: Kaizen, Reengineering, Benchmarking and PDCA.

And from these concepts, produces reflections, emphasizing the growing human role in organizations.

Concludes the article by showing the importance of people in an organization.
Este artículo promueve reflexiones con el fin de ayudar en la organización y procesos de reeducación a través de personas, es decir, profesionales en la organización.

Para ello, las organizaciones modernas contextualiza el marco de la calidad, cuatro conceptos o técnicas de extracción: Kaizen, reingeniería, Benchmarking y PDCA.

$Y$ de estos conceptos, produce reflexiones, destacando el creciente papel humano en las organizaciones.

El artículo concluye mostrando la importancia de las personas en una organización.
Palavras-chave: $A j f d s j f h j d s h f d s h f d s f d s f$.

\section{Autores:}

Ricardo Gaz

Titulação: Doutor em Ciências da Engenharia de Produção (COPPE-UFRJ) e professor titular da Estácio de Sá.

Email: ricgaz@gmail.com

"Se queres colher em três anos, plante trigo. Se queres colher em dez anos, plante uma árvore. Mas se queres colher para sempre, desenvolva o ser humano".

Provérbio Chinês

"Se queres colher em três anos, plante competência técnica e excelência humana na organização. Se queres colher em dez anos, plante mais competências técnicas e excelências humanas na organização. Mas se queres colher para sempre, oportunize-as elou desenvolva-as em todos os profissionais da organização, sempre."

Ricardo Gaz

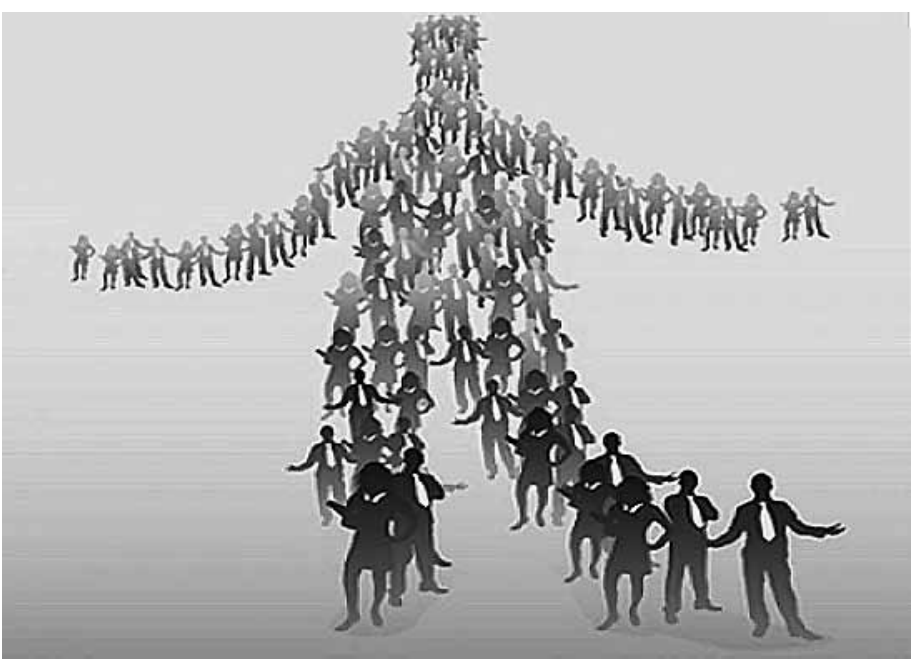

Figura 1 - Profissionais Unidos com Excelências Humanas e Competências Técnicas

\section{Introdução}

Os processos de uma organização continuam sempre sendo realizados ou liderados por pessoas, independente do seu nível tecnológico e tipologia organizacional, caracterizando assim o valor humano (CROSBY, 1979, 1992; DEMING, 1990).

Neste contexto, reflexões crescentes são apresentadas, enfatizando o papel humano nas organizações somado 
a criação de um modelo de crescimento organizacional sustentável.

Em sendo a abordagem qualitativa considerada a mais adequada para a pesquisa e metodologia, conforme ensina Creswel (2007), sobre a pesquisa qualitativa ser fundamentalmente interpretativa, o presente artigo realiza interpretações sobre quatro conceitos da Qualidade com objetivo de educar as organizações a partir de seus profissionais.

A conclusão enfatiza como é fundamental existir profissionais capacitados, motivados e educados de modo a gerar uma organização triunfante, mas sempre respeitando o ser humano (GAZ, 1998; GAZ, 2002).

\section{Contextualização}

Partindo-se do pressuposto de que o ser humano sempre foi o agente detonador de novos paradigmas nas organizações a partir de sua tomada de decisão gerando uma ação, seja esta ação em nível: operacional, tático ou estratégico.

Neste sentido, toda modelagem estratégica, processo decisório e respectivas ações, em todos esses três níveis, somente podem ser realizados por pessoas.

Em outras palavras, o processo decisório e o mapa estratégico são partes fundamentais para que uma organização triunfe no mercado (MINTZBERG, 2000; PORTER, 1996; PRAHALAD, 1994).

Munir com conhecimentos os profissionais, gestores, líderes e donos de uma organização é uma condição fundamental para instrumentalizá-los em termos de decisões, em todos os níveis (GAZ, 2006).

Dessa forma, o processo decisório torna-se uma responsabilidade e uma competência formal que, além das informações obtidas no processo avaliativo, utiliza seu conhecimento pessoal: referências educacionais, técnicas, políticas, institucionais, sociais, culturais, espirituais, acrescentando a percepção que tem do(s) problema(s), formando uma convicção, tomando decisão e mobilizando recursos necessários para respectiva ação.

No âmbito organizacional como um todo, o processo decisório é complexo, variado e permeado de subjetividade assim como incertezas e riscos já que envolve seres humanos em sua "ponta final": clientes.

No âmbito de políticas, planejamento e gestão, é importante entender que há também momentos em que faltam conhecimentos para um adequado processo decisório, há outros em que existem conhecimentos suficientes, mas que o processo decisório é adiado e, ainda, há outros momentos em que o processo decisório é necessário ser implementado mesmo diante de escassas evidências e informações.

Outro ponto importante é que o processo decisório inicia-se desde o momento em que o gestor, líder, profissional, dono de uma organização, idealiza algo, projeta e/ou recebe resultados de uma avaliação e precisa decidir até culminar em ações de forma a empreender, solucionar um problema - preventivo e/ou corretivo que lhe deu origem, entre outros (GAZ, 2006).

Mais ainda complexo se torna contextualizar os resultados da avaliação dentro dos vários cenários e fatores que lhe são próprios: questões estratégicas, sociais, políticas, econômicas, religiosas, circunstanciais - oportunidades e/ou necessidades, enfim, os diversos fatores que afetam a gestão de uma organização, e formar uma conviç̧ão que permite realizar um adequado processo decisório.

Este artigo, portanto, aborda importantes instrumentos que auxiliarão em uma reeducação organizacional, em seus processos e em seus profissionais.
Especificamente, a seguir são apresentados quatro conceitos $^{1}$ : Kaizen, Reengenharia, Benchmarking e PDCA (JURAN, 1980; UMEDA, 1990; TEBOUL, 1991), percebendo que todos servem para instrumentalizar um profissional, gestor e/ou líder, mas nenhum projeto ou empreendimento alcançou, alcança ou alcançará excelência exclusivamente por eles. Isto é, essa instrumentalização e munição de conhecimentos a partir dos quatro conceitos são partes da excelência ou do ser total: da competência técnica, e a outra parte: a excelência humana (GAZ, 1998).

No fundo, esta excelência ou ser total é tudo que toda organização almeja, e neste contexto, ao longo do artigo, enfatiza-se a irrefutabilidade do valor humano para tal, em todos os seus processos e sua gestão (CROSBY, 1979, 1992; DEMING, 1990).

\section{Melhoria Contínua ou Kaizen}

"Engaje todos da empresa no processo de realizar a transformação. A transformação é da competência de todo mundo". (Deming)

"Um homem não deveria nunca parar de aprender, nem no seu último dia". (Moisés Maimônides)

\section{"Defeitos não fazem mal, quando há vontade e poder de os corrigir". (Machado de Assis) \\ “O sábio envergonha-se dos seus defeitos, mas não se envergonha de os corrigir". (Confúcio)}

No contexto organizacional, melhorar por melhorar não tem fundamento em si mesmo. Pode ser que ao contrário, a considerada melhora traga pioras.

Por outro lado, ficar paralisado também nada adianta se o processo não melhora, somente piora ou ainda nada pode ser feito para melhorá-lo.

É preciso reconhecer que em todo processo de uma organização há sempre causa(s): medição, materiais, mão de obra, máquinas, métodos e meio ambiente; e efeito(s), sendo, portanto, possível de se melhorar esse(s) efeito(s) focando-se nessa(s) causa(s) (ISHIKAWA, 1985).

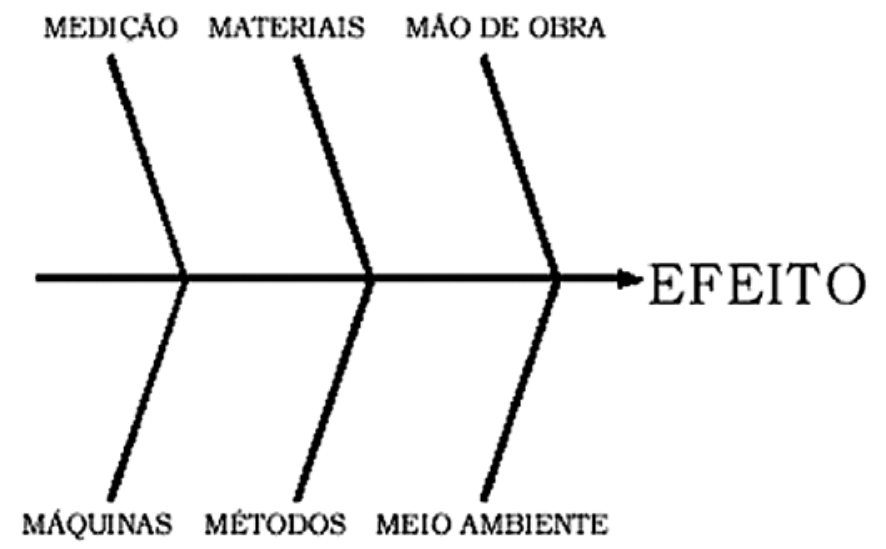

Figura 2 - Diagrama de Ishikawa

Em certos casos ou momentos são considerados todos como sendo uma ferramenta, técnica, método, conceito ou mesmo uma filosofia da gestão da qualidade. 
Historicamente, a melhoria contínua teve seu início precisamente com os primeiros trabalhos de implantação do Controle Estatístico de Processos (C.E.P.) (DEMING, 1990; JURAN; 1980).

O objetivo era de verificar ou checar (check) se o processo - gerencial, produtivo, etc., ficava fora dos limites - mínimo e máximo, e então este poderia ser melhorado de alguma forma, gradualmente.

Na prática, todos os processos de mudanças desenvolvidos com sucesso iniciam-se reduzidos, com poucos resultados e alcançados progressivamente no tempo.

Em certos casos, as melhorias podem ser concretizadas através de apenas uma equipe de trabalho. E isso implica na formação de uma equipe coesa - técnica e humanisticamente.

Conceitualmente, melhoria contínua, em japonês: kaizen, trata-se de uma abordagem incremental e participativa dos profissionais indo da qualidade intrínseca a excelência organizacional.

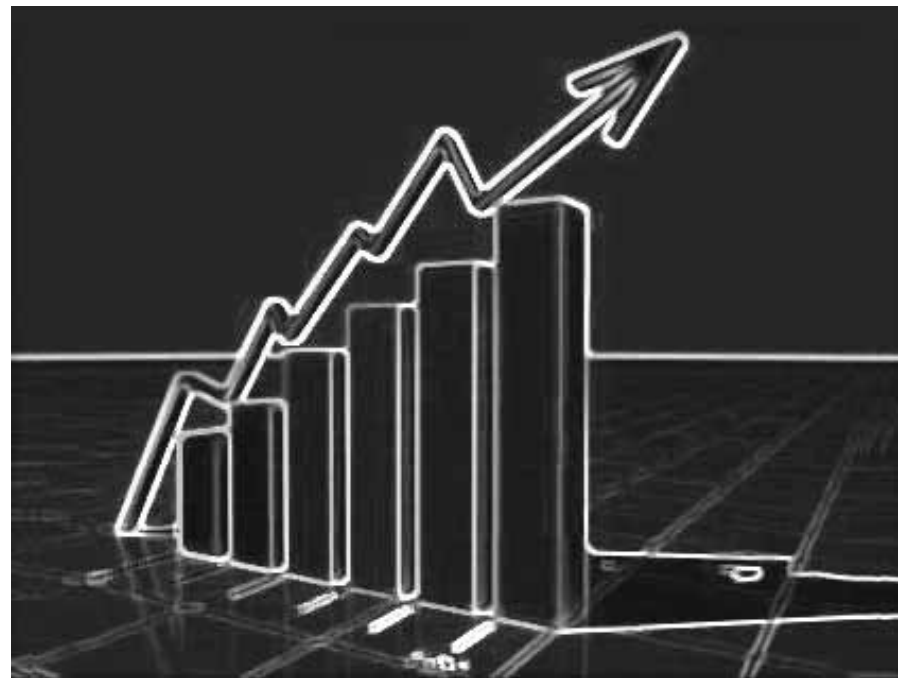

Figura 3 -Incrementos de melhoria até a Excelência

E por isso, quando há paralisação de melhorias, permanecendo muito tempo com o mesmo processo, se decresce, pois quando há movimento adequado de melhorias nos processos organizacionais, há progresso, sempre.

\section{Reengenharia, Reestruturação ou Reinvenção no Contexto Organizacional}

“A imaginação é mais importante que o conhecimento”. (Albert Einstein)

“Você deve ser a mudança que deseja ver no mundo". (Mahatma Ghandi)

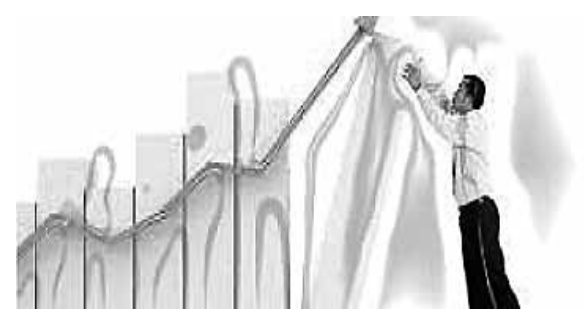

Figura 4-Reengenharia com Pessoas
A reengenharia foi uma reação ao imenso abismo existente entre as intensas e aceleradas mudanças ambientais e a incapacidade ou imobilidade das organizações em ajustar e adaptar-se às mudanças.

A reengenharia na prática resulta em uma mudança radical da estrutura, processo ou alguma atividade importante da organização (COLE, 1994; DAVENPORT, 1994; HAMMER, Michael; CHAMPY, 1993).

Ela representa uma reconstrução, indo além de uma mera melhoria pontual ou mesmo gradual.

Em síntese, para reinventar: ideias, procedimentos, processos, é preciso se reinventar em modos de pensar, sentir, falar, ver, ouvir, perceber e agir - pensar na reengenharia.

E isso tudo é feito com e por pessoas.

\section{Benchmarking}

"Todos copiam, mas nós copiamos melhor".

(um consultor japonês para um consultor americano na época da miniaturização dos aparatos eletros-eletrônico)

"Nada há de novo debaixo do sol".

(Rei Salomão - Eclesiastes, capítulo 1 versículo 18)

"Não, Tempo, não zombarás de minhas mudanças! As pirâmides que novamente construíste não me parecem novas, nem estranhas; Apenas as mesmas com novas vestimentas". (William Shakespeare)

O benchmarking foi introduzido em 1979 pela Xerox como sendo um processo contínuo de avaliar produtos, procedimentos, serviços e práticas dos concorrentes mais bem posicionados em termos mercadológicos (CAMP, 1998).

Ele visa desenvolver a habilidade dos gestores visualizarem no mercado as melhores práticas administrativas das organizações consideradas como de excelência. Disso resulta o termo bench marking - melhor prática.

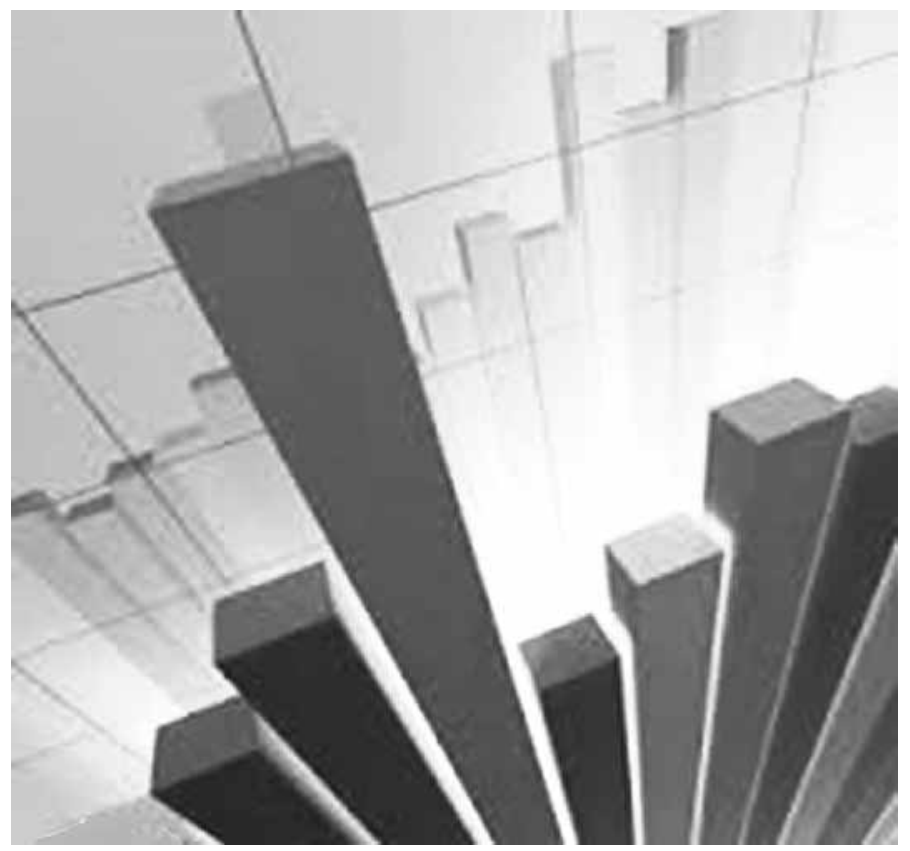

Figura 5-Benchmarking com Pessoas 
A meta é definir objetivos em gestão e legitimá-los por meio do confronto externo sem que isso denote algo destrutivo.

Ao contrário, fomenta-se a comparação como um método saudável e didático para despertar ações que as organizações com referenciais de excelência estão praticando e que servem de lição-exemplo e orientação-guia para os processos das organizações com graus menores de qualidade ou de excelência.

Em outras palavras, o benchmarking não é uma ferramenta de controle ou "pirataria". É uma ferramenta de comparação entre o que a organização está realizando e o que o mercado realiza.

No contexto interorganizacional, o benchmarking não pode ser um processo de cópia e imitação das melhores práticas - processos, produtos e/ou serviços, mas um aprendizado com elas, superando-as em criatividade, inovação, talento, por meio do empreendedorismo.

Neste contexto, algumas práticas salutares de benchmarking ocorrem, sendo uma delas, por exemplo, a visitação, a observação e o aprendizado com organizações que não fazem parte alguma da concorrência do segmento em que a organização visitante atua.

Outrossim, é possível de se ter as melhores práticas ou mudanças para melhor dentro da própria organização, pelas pessoas, desde que fomentadas com a devida motivação.

\section{Equipes de Alto Desempenho}

"Com talento, ganhamos partidas. Com trabalho de equipe, paixão e inteligência, ganhamos campeonatos." (Michael Jordan)

\section{"Quem não tem dificuldades não cresce". (Yogananda)}

Atualmente considera-se que os profissionais e sua coesão sejam fatores fundamentais para o sucesso dos processos e das organizações (ARAUJO, 2008; CHIAVENATO, 2008; KATZENBACH; SMITH, 2004).

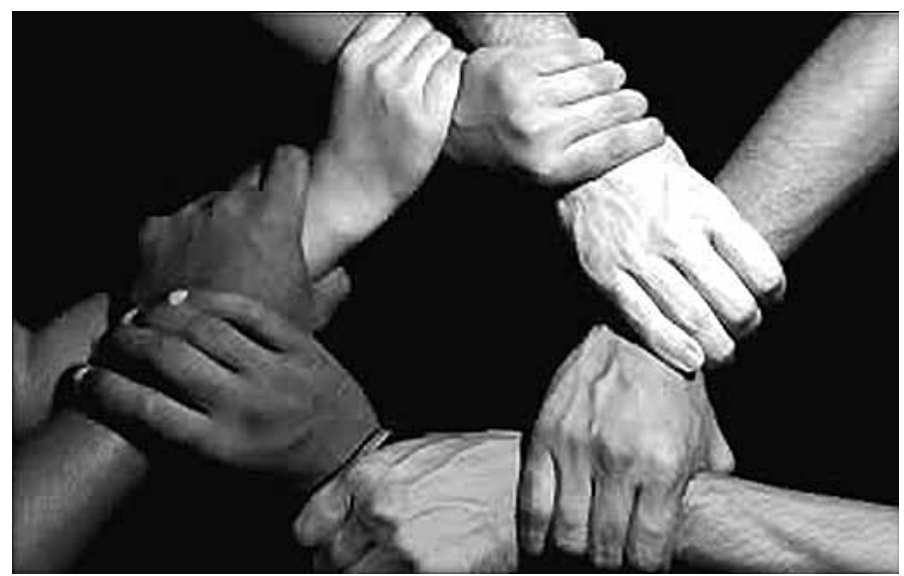

Figura 6-Coesão Humana

Em outras palavras, o trabalho em equipe com elevado desempenho pode gerar dividendos para todos da organização, mormente nos estabelecimentos modernos, não viciados na competição interna.
Sua empresa está pronta para

\section{Desenvolver Equipes de Alto Desempenho?}

\section{Figura 7 - Questionamento Organizacional rumo às Equipes de Alto Desempenho}

Para tanto é preciso desenvolver o trabalho em equipe já que é notório o benefício que uma equipe bem afinada pode trazer de dividendos para a organização, mais do que um profissional em separado, mesmo que este seja extremamente competente ou talentoso (REIS et al, 2007).

Oportuno dizer que uma equipe profissional é formada por pessoas diferentes, que trazem histórias de vida e competências diferentes, mas que precisam se relacionar bem além das questões técnicas.

Por exemplo, um profissional é excelente tecnicamente em analisar relatórios complexos; já outro disserta com fluidez e tem flexibilidade independente do público, mormente com clientes complicados; outros ainda têm uma propensão natural para detectar e resolver problemas eficaz e eficientemente.

Assim, tais potenciais inerentes em cada profissional e outros naturalmente existentes, sendo bem aproveitados, gerenciados e integrados poderão formar e resultar em uma equipe coesa, eficiente, de confiança entre si e naturalmente com elevado desempenho.

Certamente, o líder, gestor e/ou coordenação de uma organização deverá ser responsável por esse item, pois é mais raro ocorrer uma coesão e equipes de elevado desempenho sem a visão de um líder que tem por pressuposto conhecer os potenciais e também fragilidades de cada um.

Em síntese e na prática, o objetivo é obter a participação contínua, ativa e criativa dos profissionais, buscando respostas rápidas às mudanças além de permitir atendimento, serviço ou resposta com qualidade crescente diante das demandas dos clientes.

Percebe-se que nada mais provado que a percepção de um cliente (externo) na prática de uma equipe profissional da organização através do seu tempo e qualidade de serviço desempenhada.

É facilmente identificado pelo cliente uma equipe de baixo desempenho e outra de alto desempenho.

É possível de se ter clientes da classe E sendo excelentemente tratados com a devida qualidade, em compensação ter clientes da classe A muito mal tratados.

Por outro lado, é preciso que todos os componentes da equipe trabalhem em conjunto, com as devidas competências exercidas além de uma união psicoemocional ao ponto de poderem naturalmente demonstrar aos seus clientes.

Impressionar um cliente com tecnologias avançadas, leiaute e arquitetura de ponta, não se caracterizam como uma equipe de alto desempenho. 
É também verdade que nada adianta haver equipes multidisciplinares se a linguagem, o método e a abordagem são tão divergentes entre si ao ponto de colocar o cliente em situações piores em vez de motivá-las, supri-las (às necessidades), encantá-las (oportunidades).

Futuramente, espera-se que haja equipes transdisciplinares nas organizações, falando uma mesma linguagem, sem perderem suas competências e conhecimentos especializados, mas integrados emocional e tecnicamente, pelo menos, aos quais poderão ser consideradas mediante suas práticas ao longo do tempo, como sendo uma equipe de alto desempenho.

Neste sentido, em termos globais, fazer com que todos os profissionais da organização caminhem na mesma direção pode não ser tão difícil quanto parece ou se pensa ser.

É claro que deve ser necessário aplicar muita estratégia, mediante objetivos definidos, comunicação adequada, feedbacks e contra feedbacks constantes além de uma liderança com visão e ação: positiva, inspiradora, liderada, compartilhada, específica e global ao mesmo tempo.

Dessa forma, o ideal de toda equipe-organização se caracterizando como sendo uma equipe de alta performance, onde todas as potencialidades são empregadas da melhor forma, para se atingir os objetivos estratégicos organizacionais, sem é claro excluir os de cada setor, processo e profissional - integração entre objetivos a partir da formação de equipes de elevado desempenho.

Em síntese, inexistem serviços de elevada qualidade numa organização e/ou com resultados alcançados/esperados de qualidade sem equipes de alto desempenho, de qualidade, ou seja, sem pessoas que trabalhem suas qualidades e ao mesmo tempo trabalhem em equipe e não como "eu-equipe", principalmente não trabalhando seus aspectos humanísticos e relacionais profissionalmente.

\section{Ciclo PDCA}

"A vida, para cumprir seu ciclo de evolução, deve ser como água, em permanente movimento". (Pecotche)

\section{"Felicidade é atividade".} (Aristóteles)

\section{"O homem não morre quando deixa de viver, mas sim quando deixa de amar" (Charles Chaplin)}

Se em todo procedimento de melhoria, há uma metodologia própria, mediante método previamente escolhido (parte do planejamento - plan), a execução do método (do) bem como o seu controle (check) e novas medidas no futuro (act) para que o cliente possa ser beneficiado, encantado ou preenchido (de sua necessidade), da mesma forma há um ciclo ou metodologia própria em nível técnico e ao mesmo tempo humanístico para se obter os processos administrativos em uma organização bem gerenciados.

Neste contexto, o ciclo PDCA ou também chamado de método de solução de problemas, levado para o Japão por Deming em 1950, foi criado por seu mestre na década de 20 por Shewhart (DEMING, 1990; CAMPOS, 1994, 1996, 2004).

O ciclo PDCA é um processo gerencial de tomada de decisões para obtenção de metas imprescindíveis à sobrevivência de uma organização.
É uma ferramenta que serve tanto para melhorar padrões quanto para conservar os padrões já alcançados (ANDRADE, 2003).

Há inclusive a incorporação das ferramentas da qualidade dentro da própria ferramenta do PDCA, além do adicional nele com outro método conhecido como programa seis sigma (AGUIAR, 2002).

Em síntese, todos os colaboradores da organização devem conhecer o processo, a ferramenta ou ciclo PDCA e saber a fase em que está do PDCA dentro de sua organização.

Em seguida são apontadas as principais vantagens do PDCA:

- Permite a resolução de problemas - preventivos e corretivos, de modo científico e eficaz (alcance das metas).

- Habilita a todos os profissionais da organização a resolverem os problemas que se encontram sob sua responsabilidade, função e atividade.

- É um método cíclico, que se inicia pelo planejamento (P), seguindo com a execução da ação delineada (D), verificando (C) sempre se o que foi realizado estava em conformidade ao planejado, permitindo ao gestor da organização adotar uma ação para eliminar ou ao menos atenuar a distorção ou falha (A).

Por ser um método de fácil compreensão e pragmática aplicação, tornam-se mais claros e ágeis, facilitando o cumprimento dos processos em voga.

É dividido em quatro etapas:

$\mathrm{P}($ Plan $=$ Planejar $)=$ definir as metas; definir os métodos que permitirão atingir as metas propostas (eficácia). Recomenda-se também que sejam produzidas estratégias apropriadas para que além de se alcançar as metas preestabelecidas que elas sejam alcançadas da melhor forma (eficiência).

$\mathrm{D}(D o=$ Fazer, Executar $)=$ educar e treinar; executar a tarefa. Realizar os trabalhos como foi projetado na etapa de planejamento. Buscam-se também informações que serão utilizadas na verificação do processo em questão. Nesta fase são fundamentais a educação e o treinamento no trabalho.

$\mathrm{C}($ Check $=$ Verificar, Checar $)=$ verificar os resultados da tarefa executada. Examinar se o realizado está de acordo com o planejado; Identificar as irregularidades.

A $($ Action $=$ Agir, Atuar $)=$ Atuar corretivamente. Identificadas os itens de não conformidades, definir e colocar em prática as soluções que eliminem as suas causas; Se não forem identificados desvios no processo em curso, poderá então ser realizado um trabalho de ações preventivas de problemas futuros.

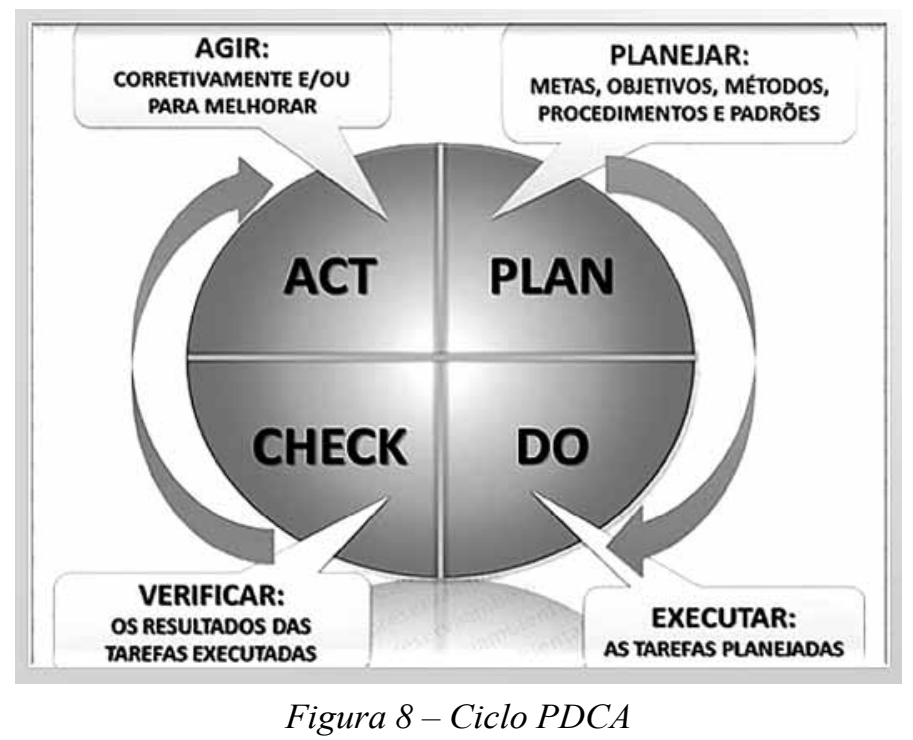


Neste contexto, em termos de estabelecimento de metas, é importante considerar que há dois tipos de metas:

1. Metas para manter ou preservar-

Exemplo: Em serviços, não ultrapassar 5 minutos o tempo de espera do cliente para ser atendido pelo profissional da organização em qualquer setor da e pela organização.

Esta é uma "meta padrão". Para alcançar metas, é necessário implantar procedimentos operacionais.

\section{Metas para melhorar -}

Exemplo: Baseado em certos dados e fatos (passados), podendo utilizar alguma ferramenta da qualidade (GAZ, 1998, 2002; BRASSARD, 1985) aumentar o faturamento da organização em $70 \%$ até janeiro de 2016 .

Para este caso será necessário ajustar os procedimentos operacionais para o alcance das novas metas e novos resultados.

Isso é possível pela melhoria contínua ou chamado de ciclos de melhoria na organização rodando-se o ciclo PDCA, indo para patamares superiores aos padrões preestabelecidos do passado, conforme é ilustrado a seguir.

\section{Ciclos de Melhoria}

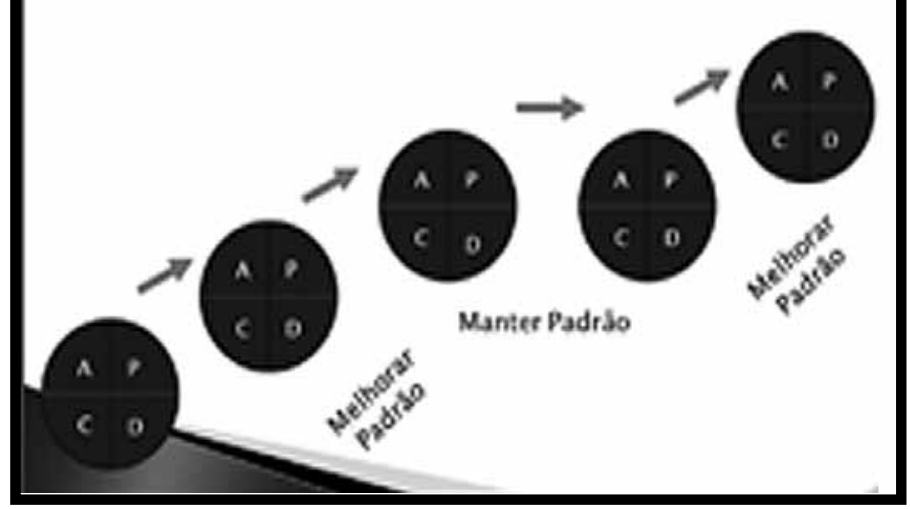

Figura 9-Ciclos de Melhoria via PDCA

Em geral, é preciso dos profissionais da organização coadunar teoria com prática e vice-versa, ver que dimensão ou quais dimensões da qualidade se está avaliando e gerenciando, os critérios que se adota para a excelência empresarial, entre outros, seja qual for o estágio ou fase em que se encontra no PDCA e seus padrões preestabelecidos de qualidade do passado rumo ao futuro. (CAMPOS, 1999; ERNEST YOUNG E AMERICAN QUALITY FOUNDATION, 1992; GARVIN, 2002; PALADINI, 2000).

\section{Considerações Finais}

O presente artigo apresentou crescentes reflexões abalizadas por quatro: ferramentas, conceitos, métodos, filosofias e/ou sistemas da qualidade - que cooperam na formação do $T Q C-$ Total Control Quality - Controle da Qualidade Total (OLIVEIRA, 2001), aplicadas há tempos por várias organizações no Brasil e no exterior.

No entanto, a abordagem diferiu-se por completo, pelo fato de ter como razão principal na implementação de modo adequado dessas quatro técnicas, as pessoas, ou seja, os seus profissionais como fatores diferenciais em suas aplicações nos processos e resultados organizacionais.

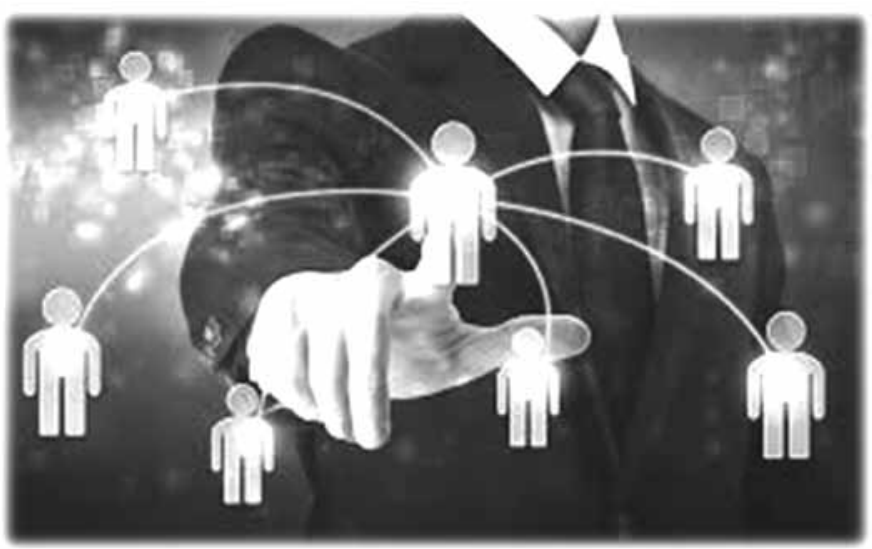

Figura 10-Pessoas, Equipes e consequentemente Qualidade na Organização

Outrossim, além das pessoas terem que ser capacitadas - tecnicamente, apontou também o fator humanístico onde os profissionais precisam trabalhar em equipe e com suas qualidades internas como pessoas, de modo que possam em concomitância, produzirem a qualidade - melhorias/mudanças, nos processos inter e intra-organizacionais.

No final, sinalizou dentro da ótica seguida, que é possível de se ter várias dimensões da qualidade o que consequentemente poderão nortear e afetar, positiva ou negativamente, toda a organização, tanto em termos dos processos e melhorias/mudanças quanto de seus profissionais e suas inter-relações.

\section{Referências}

AGUIAR, Silvio. Integração das ferramentas da qualidade ao PDCA e ao programa seis sigma. Belo Horizonte: Editora de Desenvolvimento Gerencial, 2002.

ANDRADE, Fábio Felipe de. O Método de melhorias PDCA. São Paulo: USP, 2003.

ARAUJO, L.C.G. Gestão de pessoas: Estratégias e integração organizacional. São Paulo: Atlas, 2008

BRASSARD, Michael. Qualidade. Ferramentas para uma melhoria contínua. Rio de Janeiro: Qualitymark, 1985.

CAMP, Robert C. Benchmarking - o caminho da qualidade total, 3. ed., São Paulo: Pioneira, 1998.

CAMPOS, Vicente F. TQC: gerenciamento da rotina do trabalho do dia-a-dia. Belo Horizonte: Fundação Christiano Ottoni, 1994.

Gerenciamento pelas diretrizes. Belo Horizonte: Fundação

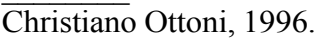

Controle da qualidade total (no estilo japonês). Belo Horizonte: Editora de Desenvolvimento Gerencial, 1999.

Como definir os seus problemas. In: Gerenciamento da rotina do trabalho do dia-a-dia. Nova Lima: INDG Tecnologia e Serviços Ltda., p.106, 2004.

CHIAVENATO, I. Gestão de pessoas: o novo papel dos recursos humanos nas organizações. 3. ed. Rio de Janeiro: Elsevier, 2008.

COLE, Robert E. Reengineering the corporation: a review essay. Quality Management Journal, July 1994.

CROSBY, Philip B. Quality is free. New York: New American Library, 1979. 
Zero Defects. Quality Progress, Febr. 1992.

DAVENPORT, Thomas H. Reengenharia de processos. Rio de Janeiro: Campus, 1994.

DEMING, W. Edwards. Quality, productivity and competitive position. Boston: MIT Press, 1982.

. Qualidade: a revolução da administração. Rio de Janeiro: Marques Saraiva, 1990.

ERNEST YOUNG E AMERICAN QUALITY FOUNDATION. International quality study: a definitive report on international industry-specific quality management practices. Cleveland: Ernest Young \& American Quality Foundation, 1992.

FNQ. Cadernos de Excelência - Processos. São Paulo: Fundação Nacional da Qualidade, 2007.

GARVIN, David A. Gerenciando a qualidade: a visão estratégica e competitiva. Rio de Janeiro: Qualitymark, 2002.

GAZ, Ricardo. Um estudo e experimento de raciocínio com integração emocional em processos decisórios empresariais. 2006. $222 \mathrm{f}$. Tese (Doutorado) - Universidade Federal do Rio de Janeiro, COPPE, Rio de Janeiro, 2006.

, Ser Total: reflexões triunfantes para as organizações triunfantes, respeitando o ser humano. Rio de janeiro: Suma Econômica, 2002.

, Ser Total: reflexões para as organizações triunfantes, respeitando o ser humano. São Paulo: Escala, 1998.

HAMMER, Michael; CHAMPY, James. Reengineering the corporation. New York: Harper Business, 1993.

ISHIKAWA, Kaoru. How to operate QC circles activities. Tokio: JUSE, 1985.

JURAN, Joseph M.; GRYNA JR., Frank M. Quality planning and analysis. New York: McGraw-Hill, 1980.

KATZENBACH, J.R.; SMITH, D.K: Equipes de alta performance: Conceitos, princípios e técnicas para potencializar o desempenho das equipes. Rio de Janeiro: Elsevier, 2001.

MINTZBERG, Henry; AHLSTRAND, Bruce; LAMPEL, Joseph. Safári de estratégia. Porto Alegre: Bookman, 2000.

NONAKA, Ikujiro.; TAKEUSHI, Hirotaka. The knowledge creating company: how japanese companies create the dynamics of innovation. New York: Oxford University Press, 1995.

OLIVEIRA, Marcos A. L. ISO 9001/2000: rumo ao TQC. Banas Qualidade, set. 2001.

PALADINI, Edson P. Gestão da qualidade: teoria e prática. São Paulo: Atlas, 2000.

PORTER, Michael E. What is strategy? Harvard Business Review, Boston, Nov./Dec. 1996.

PRAHALAD, C. K.; HAMEL, Gary. Competing for the future. Boston: Harvard Business School Press, 1994.

REIS, A.M.V. et al. Desenvolvimento de equipes. Rio de Janeiro: FGV, 2007.

SHEWHART, W. A. The economic control of quality manufactured product. Milwaukee: ASQC,1981.

SILVA, João M. O ambiente da qualidade. Belo Horizonte: Fundação Christiano Ottoni, 1996.

TÉBOUL, James. Gerenciando a dinâmica da qualidade. Rio de Janeiro: Qualitymark, 1991.

UMEDA, Masao. ISO e TQC: o caminho em busca da GQT. Belo Horizonte: Fundação Christiano Ottoni, 1996. 